\title{
Severidade da mancha-de-alternária em cultivares de girassol na região do Cerrado do Distrito Federal ${ }^{(1)}$
}

\author{
Renato Fernando Amabile ${ }^{(2)}$, Caroline Machado Vasconcelos ${ }^{(3)}$ e Antônio Carlos Gomes ${ }^{(2)}$
}

\begin{abstract}
Resumo - Avaliou-se a severidade da mancha-de-alternária (Alternaria helianthi) em cinco genótipos de girassol (Helianthus annuus L.), em duas densidades populacionais e duas épocas de semeadura. Os experimentos foram conduzidos no campo experimental da Embrapa-Centro de Pesquisa Agropecuária dos Cerrados, em Planaltina, DF, no ano agrícola de 1998/1999, num Latossolo areno-argiloso. O delineamento experimental utilizado foi o de blocos ao acaso, num esquema fatorial de $5 \times 2$, com três repetições. A porcentagem de plantas com sintomas da mancha foi estimada por meio de observações semanais, empregando-se notas de 0 a 5 nos terços inferior, médio e superior da planta. A população de plantas não influenciou na incidência de alternária. Todas as cultivares estudadas foram suscetíveis à doença. As condições climáticas transcorridas em cada época de semeadura modificaram a severidade da doença.
\end{abstract}

Termos para indexação: Helianthus annuus, Alternaria helianthi, época de semeadura, população de plantas.

\section{Severity of alternaria in sunflower crop in the Cerrado region of Federal District, Brazil}

\begin{abstract}
Severity of alternaria leaf spot was evaluated in five genotypes of sunflower as a result of two densities of population and two sowing dates. The experiments were conducted in the EmbrapaCentro de Pesquisa Agropecuária dos Cerrados experimental field, at Planaltina, DF, Brazil, on the crop season of 1998/1999 on an Oxisol soil. The experimental design was in randomized blocks in a $5 \times 2$ factorial with three replicates. The percentage of infected plants was estimated based on weekly observations considering scores from 0 to 5 in lower, middle and upper parts of the plant. The occurrence of alternaria was not influenced by density of population of 42,000 or 49,000 plants $/$ ha. All cultivars were susceptible to the disease. The climatic conditions for each sowing date changed the disease severity.
\end{abstract}

Index terms: Helianthus annuus, Alternaria helianthi, sowing date, plant population.

\section{Introdução}

A falta de otimização da interação genótipo x latitude ou época de semeadura $\mathrm{x}$ densidade populacional (Lawn \& Williams, 1987) afeta o desenvolvimento ou o crescimento das plantas, e, conseqüentemente, a presença de doenças. A época de semeadura influencia, ainda, no controle das pragas e doenças que atacam a

(1) Aceito para publicação em 23 de maio de 2001.

(2) Embrapa-Centro de Pesquisa Agropecuária dos Cerrados (CPAC), Caixa Postal 08233, CEP 73301-970 Planaltina, DF. E-mail: amabile@cpac.embrapa.br, acarlos@cpac.embrapa.br

(3) Universidade de Brasília, Fac. de Agronomia e Veterinária, Caixa Postal 04508, CEP 70919-970 Brasília, DF. Bolsista do Programa Pibic CNPq/UnB. E-mail: wong@zaz.com.br cultura (Charlet \& Busacca, 1986), afeta o rendimento, a porcentagem de óleo, e a altura e o diâmetro do capítulo do girassol (Alessi et al.,1977; Seiler, 1983; Kinman \& Sarle, 1984).

A influência da densidade de plantas na determinação do microclima na cultura inicia-se com a emergência das plântulas, as quais vão cada vez mais reduzindo a passagem do vento, sombreando o solo e alterando a umidade relativa, provocando o aumento da incidência de doenças, o acamamento de plantas e a diminuição do diâmetro do capítulo. Isso se deve à capacidade de compensação que a planta apresenta através do aumento do capítulo quando em densidades mais baixas. A faixa de densidade de semeadura mais recomendada, no Sul do Brasil, situa-se entre 36 mil e 46 mil plantas/ha (Castiglioni et al., 1994). 
A mancha-de-alternária, causada pelo fungo Alternaria helianthi (Hansf.) Tubaki \& Nishihara, é o principal problema fitossanitário do girassol (Moraes et al., 1983). Descrita pela primeira vez em Uganda por Hansford (1943), ela tem sido relatada em todas as áreas de cultivo do mundo. Carson (1982) constatou que as perdas na produtividade, a redução do teor de óleo e do peso hectolítrico das sementes têm alta correlação com a ocorrência dessa doença.

Quando a severidade é crítica, causa pontuações necróticas que coalescem, formando áreas extensas de tecido necrosado, provocando crestamento prematuro da folha, desfolha precoce, e morte das plantas (Leite, 1997).

As condições ótimas para a germinação de conídios de $A$. helianthi são: alta umidade relativa e temperatura entre 25 a $30^{\circ} \mathrm{C}$ (Sentelhas et al., 1996), desde que haja presença de água líquida sobre as folhas para propiciar a germinação e penetração dos esporos. Assim, são as condições climáticas predominantes no período de cultivo que determinam a intensidade da doença. Na prevenção de doenças, Castro et al. (1996) recomendam utilizar época de semeadura adequada para cada região, uso de materiais genéticos e densidade de plantas segundo orientação da pesquisa, rotação de culturas por quatro anos, e tratamento de sementes.

O objetivo do presente trabalho foi avaliar a severidade da mancha-de-alternária em cinco genótipos de girassol, em duas densidades populacionais e em duas épocas de semeadura.

\section{Material e Métodos}

Os experimentos foram conduzidos no ano agrícola de 1998/1999, na Embrapa-Centro de Pesquisa Agropecuária dos Cerrados (CPAC), em Planaltina, DF, situada a $15^{\circ} 35^{\prime} 30^{\prime \prime}$ de latitude $\mathrm{S}, 47^{\circ} 42^{\prime} 30^{\prime \prime}$ de longitude $\mathrm{O}$ e a altitude de $1.007 \mathrm{~m}$, num Latossolo areno-argiloso. Os resultados das análises do solo $(0-10 \mathrm{~cm})$ indicaram: $\mathrm{pH}$ em $\mathrm{H}_{2} \mathrm{O}$ de 6,$0 ; 25,9 \mathrm{~g} \mathrm{~kg}^{-1}$ de $\mathrm{MO} ; 0,7 \mathrm{mmol}_{\mathrm{c}} \mathrm{dm}^{-3} \mathrm{de}$

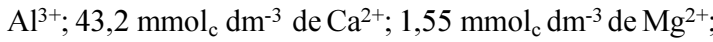
$3,01 \mathrm{mg} \mathrm{dm}^{-3} \mathrm{de}$ P; $1,87 \mathrm{mmol}_{\mathrm{c}} \mathrm{dm}^{-3} \mathrm{de} \mathrm{K} ; 130 \mathrm{~g} \mathrm{~kg}^{-1} \mathrm{de}^{-1}$ areia grossa; $400 \mathrm{~g} \mathrm{~kg}^{-1}$ de areia fina; $100 \mathrm{~g} \mathrm{~kg}^{-1}$ de silte; $370 \mathrm{~g} \mathrm{~kg}^{-1}$ de argila.

O clima, conforme a classificação de Köppen, é do tipo Aw. Os dados meteorológicos coletados na Estação Meteorológica da Embrapa-CPAC durante o ciclo de culti- vo do girassol na condução dos experimentos são apresentados na Tabela 1.

O delineamento experimental utilizado foi de blocos ao acaso, num esquema-fatorial $5 \times 2$ (cinco cultivares de girassol: EMBRAPA-122, Rumbosol-91, C-11, M-742, M-734, e duas épocas de semeadura: 9/11/1998 e 19/11/1998) com três repetições. As densidades empregadas foram 42 mil e 49 mil plantas ha ${ }^{-1}$, utilizando-se um espaçamento entre linhas de $0,80 \mathrm{~m}$. Cada parcela foi constituída de quatro linhas de $7 \mathrm{~m}$, cuja área total era de $16,0 \mathrm{~m}^{2}$ e a área útil de $6,4 \mathrm{~m}^{2}$.

O preparo do solo constou da incorporação dos restos culturais, utilizando um arado de discos, seguido de uma gradagem com a grade niveladora. Foi aplicado o herbicida Trifluralin na dosagem de 1,8 $\mathrm{L} \mathrm{ha}^{-1}$. Em seguida, os sulcos de semeadura foram abertos mecanicamente.

Aplicaram-se, manualmente, $450 \mathrm{~kg} \mathrm{ha}^{-1}$ da fórmula 4-30-16 + Zn, e mais $30 \mathrm{~kg} \mathrm{ha}^{-1}$ de bórax. Em cobertura foram aplicados $45 \mathrm{~kg} \mathrm{ha}^{-1}$ de $\mathrm{N}$ aos 25 e aos 40 dias após a emergência das plantas.

As avaliações da doença foram feitas semanalmente, aos 30, 37, 44, 51, 58, 65, 72 e 79 dias após a emergência das plantas, através da porcentagem de folhas com sintomas nos terços inferior, médio e superior da planta de cada parcela. Atribuíram-se notas de 0 a 5 , em cada um dos terços da planta, de acordo com o seguinte critério: 0: ausência de doença; $1: 0 \%$ a $0,3 \%$ das folhas com sintomas; 2: $0,4 \%$ a $3 \%$ das folhas com sintomas; $3: 4 \%$ a $12 \%$ das folhas com sintomas; $4: 13 \%$ a $25 \%$ das folhas com sintomas; 5: 26 a $40 \%$ das folhas com sintomas (Leite et al., 1999).

Para a análise de variância, os dados originais foram transformados em $(x+0,5)^{0,5} \mathrm{e}$ as médias foram comparadas pelo teste de Tukey a $5 \%$ de probabilidade.

\section{Resultados e Discussão}

O fator população e a interação deste com as cultivares não influenciaram na incidência de alternária, tanto na primeira como na segunda época de semeadura. Em todas as partes da planta e nas duas épocas de plantio, houve significância das cultivares, das avaliações, e da interação entre cultivar versus avaliação. A interação tripla dos fatores cultivar, população e avaliação não foi significativa nas épocas estudadas (Tabela 2). Já a época de avaliação e a interação desta com as cultivares afetaram a severidade da mancha-de-alternária, em todas as partes da planta na primeira época de semeadura, e apenas na parte inferior na segunda época. 
A parte superior da planta, em ambas as épocas estudadas, foi menos infectada pelo fungo (Tabelas 3 e 4). Leite (1997) também constatou que a doença incide com mais intensidade na parte inferior da planta, avançando rapidamente para as folhas do ponteiro.

Aos trinta dias após a germinação, todas as cultivares, à exceção da M-742, na primeira época, e da EMBRAPA-122, na segunda, já apresentavam sintomas da mancha-de-alternária nas partes inferior, média e superior da planta. A cultivar M-742 não apresentou a doença na parte superior na pri- meira época, provavelmente pelo fato de a relação ciclo (germinação-florescimento)/precipitação ser uma das mais baixas. Por outro lado, na segunda época, a severidade da doença observada na EMBRAPA-122 foi conseqüência da baixa precipitação $(367,7 \mathrm{~mm})$ ocorrida no período da germinação ao início do florescimento, e também conseqüência da precocidade desse material genético, favorecendo, dessa forma, o escape da doença.

A partir da sexta avaliação (65 dias) da primeira época e da quinta avaliação (58 dias) da segunda época, excluindo-se a M-742, a incidência da alternária

Tabela 1. Dados climatológicos referentes à primeira e segunda épocas de semeadura de girassol nos períodos da germinação (15/11, 1a época e 25/11, 2a época) ao início do florescimento, e ao final do florescimento, e do final do florescimento à maturação fisiológica.

\begin{tabular}{|c|c|c|c|c|c|c|}
\hline Cultivares & $\begin{array}{l}\text { Início do } \\
\text { florescimento } \\
\text { (dia/mês) }\end{array}$ & $\begin{array}{l}\text { Temperatura máxima } \\
\text { do ar }\end{array}$ & $\begin{array}{l}\text { Temperatura } \\
\text { mínima do ar }\end{array}$ & $\begin{array}{l}\text { Temperatura média } \\
\text { do ar }\end{array}$ & $\begin{array}{c}\text { Umidade relativa } \\
\text { do ar }(\%)\end{array}$ & $\begin{array}{c}\text { Precipitação } \\
\text { (mm) }\end{array}$ \\
\hline & \multicolumn{6}{|c|}{ Germinação ao início do florescimento - $1^{\text {a }}$ época } \\
\hline EMBRAPA-122 & $30 / 12$ & 27,82 & 18,15 & 22,00 & 86,04 & 268,7 \\
\hline C-11 & $13 / 1$ & 27,60 & 18,13 & 21,91 & 86,56 & 481,8 \\
\hline M-742 & $9 / 1$ & 27,74 & 18,16 & 21,97 & 86,48 & 397,1 \\
\hline M-734 & $11 / 1$ & 27,67 & 18,14 & 21,95 & 86,37 & 459,8 \\
\hline Rumbosol-91 & $20 / 1$ & 27,74 & 18,11 & 22,04 & 84,38 & 495,0 \\
\hline \multirow[t]{2}{*}{ Média } & & 27,71 & 18,14 & 21,97 & 85,97 & 420,5 \\
\hline & \multicolumn{6}{|c|}{ Germinação ao final do florescimento - $1^{\mathrm{a}}$ época } \\
\hline EMBRAPA-122 & $9 / 1$ & 27,74 & 18,16 & 21,97 & 86,48 & 397,1 \\
\hline $\mathrm{C}-11$ & $22 / 1$ & 27,79 & 18,06 & 22,05 & 85,21 & 498,9 \\
\hline M-742 & $18 / 1$ & 27,66 & 18,17 & 21,97 & 86,18 & 495,0 \\
\hline M-734 & $20 / 1$ & 27,74 & 18,11 & 22,04 & 85,52 & 495,0 \\
\hline Rumbosol-91 & $30 / 1$ & 27,91 & 18,11 & 22,16 & 84,38 & 514,0 \\
\hline \multirow[t]{2}{*}{ Média } & & 27,77 & 18,12 & 22,04 & 85,55 & 480,0 \\
\hline & \multicolumn{6}{|c|}{ Final do florescimento à maturação fisiológica - $1^{\mathrm{a}}$ época } \\
\hline EMBRAPA-122 & $2 / 2$ & 28,88 & 17,76 & 22,84 & 77,16 & 122,1 \\
\hline $\mathrm{C}-11$ & $11 / 2$ & 29,44 & 17,72 & 23,10 & 75,44 & 20,2 \\
\hline M-742 & $6 / 2$ & 29,55 & 17,70 & 23,30 & 73,45 & 24,1 \\
\hline M-734 & $7 / 2$ & 29,52 & 17,66 & 23,15 & 74,60 & 24,1 \\
\hline Rumbosol-91 & $17 / 2$ & 29,78 & 17,30 & 22,96 & 75,30 & 20,2 \\
\hline \multirow[t]{2}{*}{ Média } & & 29,43 & 17,62 & 23,07 & 75,19 & 42,1 \\
\hline & \multicolumn{6}{|c|}{ Germinação ao início do florescimento - $2^{\mathrm{a}}$ época } \\
\hline EMBRAPA-122 & $11 / 1$ & 27,49 & 18,22 & 21,94 & 86,43 & 367,7 \\
\hline C-11 & $22 / 1$ & 27,67 & 18,11 & 22,06 & 85,06 & 406,8 \\
\hline M-742 & $18 / 1$ & 27,51 & 18,25 & 21,97 & 86,2 & 402,9 \\
\hline M-734 & $20 / 1$ & 27,61 & 18,18 & 22,05 & 85,42 & 402,9 \\
\hline Rumbosol-91 & $27 / 1$ & 27,83 & 18,15 & 22,20 & 84,00 & 406,8 \\
\hline \multirow[t]{2}{*}{ Média } & & 27,62 & 18,18 & 22,04 & 85,42 & 397,4 \\
\hline & \multicolumn{6}{|c|}{ Germinação ao final do florescimento - $2^{\mathrm{a}}$ época } \\
\hline EMBRAPA-122 & $19 / 1$ & 27,56 & 18,19 & 22,00 & 85,83 & 402,9 \\
\hline C-11 & $30 / 1$ & 27,82 & 18,16 & 22,19 & 84,13 & 421,9 \\
\hline M-742 & $25 / 1$ & 27,80 & 18,12 & 22,18 & 84,17 & 406,8 \\
\hline M-734 & $27 / 1$ & 27,83 & 18,15 & 22,20 & 84,00 & 406,8 \\
\hline Rumbosol-91 & $5 / 2$ & 28,01 & 18,08 & 22,28 & 83,09 & 421,9 \\
\hline \multirow[t]{2}{*}{ Média } & & 27,80 & 18,14 & 22,17 & 84,24 & 412,1 \\
\hline & \multicolumn{6}{|c|}{ Final do florescimento à maturação fisiológica - $2^{\mathrm{a}}$ época } \\
\hline EMBRAPA-122 & $10 / 2$ & 29,85 & 17,95 & 23,43 & 74,00 & 29,5 \\
\hline $\mathrm{C}-11$ & $19 / 2$ & 30,17 & 18,06 & 23,47 & 74,52 & 25,6 \\
\hline M-742 & $14 / 2$ & 29,82 & 18,14 & 23,31 & 75,90 & 25,6 \\
\hline M-734 & $15 / 2$ & 29,82 & 18,16 & 23,28 & 76,05 & 25,6 \\
\hline Rumbosol-91 & $25 / 2$ & 30,34 & 18,32 & 23,70 & 73,81 & 10,5 \\
\hline Média & & 30,00 & 18,12 & 23,44 & 74,86 & 23,4 \\
\hline
\end{tabular}


na parte inferior alcançou a nota máxima de 5 , mostrando a susceptibilidade dos materiais a essa doença. Tal fato se deve, provavelmente, à alta umidade relativa do ar e ao acúmulo de precipitação ocorrida durante a condução do experimento.

A média de precipitação total na primeira época de semeadura foi de $420,5 \mathrm{~mm}$, e de $397,4 \mathrm{~mm}$ na segunda, durante todo o ciclo da cultura. Isso mostra que a chuva, além de propiciar água líquida sobre as folhas para complementação dos processos de germinação e penetração do patógeno através dos estômatos, também favoreceu a dispersão do fungo por meio de respingos (Eversmeyer \& Burleigh, 1970; Frezzi et al., 1979).

Os valores climáticos que favoreceram o apare- cimento da doença foram a temperatura média do ar entre $21,9^{\circ} \mathrm{C}$ e $23,7^{\circ} \mathrm{C}$ e umidade relativa do ar entre $73,0 \%$ e $87,0 \%$, o que está de acordo com os dados obtidos por Sentelhas et al. (1996), mas discorda dos dados obtidos por Borkar \& Patil (1995). Estes autores verificaram que temperatura do ar entre $25,9^{\circ} \mathrm{C}$ e $33,7^{\circ} \mathrm{C}$ e umidade relativa do ar entre $89,0 \%$ e $95,0 \%$ permitiram o desenvolvimento da doença.

Na parte média do girassol, onde há o maior índice foliar, houve ampla variação estatística da incidência da doença. Nas duas épocas avaliadas, a porcentagem de folhas com sintomas do ataque pelo fungo alcançou aproximadamente $25 \%$. Na última avaliação, realizada 79 dias após a germinação, a M-742 apresentou de $4 \%$ a $25 \%$ de folhas infectadas.

Tabela 2. Quadrados médios da análise de variância referente à severidade de alternária nas folhas das partes inferior, média e superior das plantas de girassol, provenientes das duas épocas de semeadura.

\begin{tabular}{|c|c|c|c|}
\hline Fonte de variação & GL & 1a época & $2^{a}$ época \\
\hline & & \multicolumn{2}{|c|}{ Parte inferior da planta } \\
\hline Repetição & 2 & $0,0076331^{\mathrm{ns}}$ & $0,0015642^{\mathrm{ns}}$ \\
\hline Cultivar & 4 & $0,0134524 *$ & $0,0315096^{*}$ \\
\hline População & 1 & $0,0137669^{\mathrm{ns}}$ & $0,0081263^{\mathrm{ns}}$ \\
\hline Cultivar X população & 4 & $0,0086953^{\text {ns }}$ & $0,0112155^{\mathrm{ns}}$ \\
\hline Resíduo (a) & 18 & 0,0041696 & 0,0079744 \\
\hline Parcelas & 29 & & \\
\hline Época de avaliação & 7 & $0,0540271 * *$ & $0,4374541 * *$ \\
\hline Cultivar X época de avaliação & 28 & $0,0144320 * *$ & $0,016979 * *$ \\
\hline População X época de avaliação & 7 & $0,0035148^{\mathrm{ns}}$ & $0,0057629^{\mathrm{ns}}$ \\
\hline Cultivar X população X época de avaliação & 28 & $0,0053619^{\mathrm{ns}}$ & $0,0051714^{\mathrm{ns}}$ \\
\hline Resíduo (b) & 140 & 0,0038283 & 0,0046226 \\
\hline \multirow[t]{2}{*}{ Total } & 239 & & \\
\hline & & \multicolumn{2}{|c|}{ Parte média da planta } \\
\hline Repetição & 2 & $0,0041209^{\mathrm{ns}}$ & $0,0337133^{\mathrm{ns}}$ \\
\hline Cultivar & 4 & $0,3278816 * *$ & $0,1407790 * *$ \\
\hline População & 1 & $0,0002378^{\mathrm{ns}}$ & $0,0978779^{\mathrm{ns}}$ \\
\hline Cultivar X população & 4 & $0,0643331^{\mathrm{ns}}$ & $0,0190537^{\mathrm{ns}}$ \\
\hline Resíduo (a) & 18 & 0,0346056 & 0,0120402 \\
\hline Parcelas & 29 & & \\
\hline Época de avaliação & 7 & $1,6345467 * *$ & $1,2109670 * *$ \\
\hline Cultivar X época de avaliação & 28 & $0,0466978 *$ & $0,0414516 * *$ \\
\hline População X época de avaliação & 7 & $0,0075128^{\text {ns }}$ & $0,0141549^{\mathrm{ns}}$ \\
\hline Cultivar X população X época de avaliação & 28 & $0,0194616^{\mathrm{ns}}$ & $0,0090363^{\mathrm{ns}}$ \\
\hline Resíduo (b) & 140 & 0,0293575 & 0,0145710 \\
\hline \multirow[t]{2}{*}{ Total } & 239 & & \\
\hline & & \multicolumn{2}{|c|}{ Parte superior da planta } \\
\hline Repetição & 2 & $0,1085433^{\mathrm{ns}}$ & $0,1335600^{\mathrm{ns}}$ \\
\hline Cultivar & 4 & $0,1271859^{*}$ & $0,1446824 * *$ \\
\hline População & 1 & $0,0097726^{\mathrm{ns}}$ & $0,0032663^{\mathrm{ns}}$ \\
\hline Cultivar X população & 4 & $0,0733030^{\mathrm{ns}}$ & $0,0843628^{\mathrm{ns}}$ \\
\hline Resíduo (a) & 18 & 0,0372399 & 0,0312729 \\
\hline Parcelas & 29 & & \\
\hline Época de avaliação & 7 & $2,6716888 * *$ & $1,4755937 * *$ \\
\hline Cultivar X época de avaliação & 28 & $0,0827807 * *$ & $0,0846070 * *$ \\
\hline População X época de avaliação & 7 & $0,0423597^{\mathrm{ns}}$ & $0,0040227^{\mathrm{ns}}$ \\
\hline Cultivar X população X época de avaliação & 28 & $0,0257429^{\mathrm{ns}}$ & $0,0285045^{\mathrm{ns}}$ \\
\hline Resíduo (b) & 140 & 0,0334331 & 0,0262679 \\
\hline Total & 239 & & \\
\hline
\end{tabular}

${ }^{\text {ns Não-significativo. }{ }^{*} \mathrm{e}}{ }^{* *}$ Significativo a $5 \%$ e a $1 \%$ de probabilidade, respectivamente, pelo teste $\mathrm{F}$. 
Tabela 3. Valores transformados em $(x+0,5)^{0,5}$ da severidade da mancha-de-alternária em folhas das partes inferior, média e superior de genótipos de girassol, provenientes da primeira época de semeadura, avaliados em diferentes períodos após a germinação ${ }^{(1)}$.

\begin{tabular}{|c|c|c|c|c|c|}
\hline Avaliação (dias após germinação) & EMBRAPA-122 & $\mathrm{C}-11$ & M-742 & $\mathrm{M}-734$ & Rumbosol-91 \\
\hline & \multicolumn{5}{|c|}{ Parte inferior da planta } \\
\hline 30 & $4,66 \mathrm{Aa}$ & 4,83Aab & $4,83 \mathrm{Aab}$ & $5,00 \mathrm{Aa}$ & $5,00 \mathrm{Aa}$ \\
\hline 37 & $4,66 \mathrm{Aa}$ & $5,00 \mathrm{Aa}$ & $4,50 \mathrm{ABb}$ & $4,83 \mathrm{Aa}$ & $4,83 \mathrm{Aa}$ \\
\hline 44 & $4,83 \mathrm{Aa}$ & $5,00 \mathrm{Aa}$ & $4,83 \mathrm{Aab}$ & $4,83 \mathrm{Aa}$ & $5,00 \mathrm{Aa}$ \\
\hline 51 & $5,00 \mathrm{Aa}$ & $5,00 \mathrm{Aa}$ & $5,00 \mathrm{Aa}$ & $5,00 \mathrm{Aa}$ & $5,00 \mathrm{Aa}$ \\
\hline 58 & $5,00 \mathrm{Aa}$ & $4,50 \mathrm{ABb}$ & $4,83 \mathrm{Ab}$ & $5,00 \mathrm{Aa}$ & $4,83 \mathrm{Aa}$ \\
\hline 65 & $5,00 \mathrm{Aa}$ & $5,00 \mathrm{Aa}$ & $5,00 \mathrm{Aa}$ & $5,00 \mathrm{Aa}$ & $5,00 \mathrm{Aa}$ \\
\hline 72 & $5,00 \mathrm{Aa}$ & $5,00 \mathrm{Aa}$ & $5,00 \mathrm{Aa}$ & $5,00 \mathrm{Aa}$ & $5,00 \mathrm{Aa}$ \\
\hline 79 & $5,00 \mathrm{Aa}$ & $5,00 \mathrm{Aa}$ & $5,00 \mathrm{Aa}$ & $5,00 \mathrm{Aa}$ & $5,00 \mathrm{Aa}$ \\
\hline \multicolumn{6}{|c|}{ Parte média da planta } \\
\hline 30 & 2,33Acde & 2,16 Acd & $2,00 \mathrm{Abc}$ & $2,50 \mathrm{Abc}$ & $2,66 \mathrm{Abc}$ \\
\hline 37 & $1,50 \mathrm{Ae}$ & $1,66 \mathrm{Ad}$ & $1,66 \mathrm{Ac}$ & $1,66 \mathrm{Ac}$ & $1,66 \mathrm{Ac}$ \\
\hline 44 & $2,00 \mathrm{ABde}$ & $2,16 \mathrm{ABcd}$ & $1,66 \mathrm{Bc}$ & $3,00 \mathrm{Aab}$ & $3,00 \mathrm{Aab}$ \\
\hline 51 & $2,50 \mathrm{Abc}$ & $2,66 \mathrm{Abc}$ & $2,00 \mathrm{Bbc}$ & $3,26 \mathrm{Aab}$ & 3,33Aab \\
\hline 58 & $2,50 \mathrm{Abc}$ & 2,50 Acd & $2,00 \mathrm{ABbc}$ & $3,16 \mathrm{Aab}$ & $3,00 \mathrm{Aab}$ \\
\hline 65 & $3,50 \mathrm{Aab}$ & $2,83 \mathrm{Abc}$ & $2,50 \mathrm{Abc}$ & $3,50 \mathrm{Aab}$ & $3,16 \mathrm{Aab}$ \\
\hline 72 & $3,66 \mathrm{Aa}$ & $3,66 \mathrm{Aab}$ & $2,83 \mathrm{Aab}$ & $4,00 \mathrm{Aa}$ & $2,66 \mathrm{Abc}$ \\
\hline 79 & $4,16 \mathrm{Aa}$ & $4,16 \mathrm{Aa}$ & $4,00 \mathrm{Aa}$ & $4,16 \mathrm{Aa}$ & $4,00 \mathrm{Aa}$ \\
\hline \multicolumn{6}{|c|}{ Parte superior da planta } \\
\hline 30 & $0,16 \mathrm{Ae}$ & $0,16 \mathrm{Ad}$ & $0,00 \mathrm{Ac}$ & $0,16 \mathrm{Ad}$ & $0,50 \mathrm{Ab}$ \\
\hline 37 & $0,16 \mathrm{Ae}$ & $0,16 \mathrm{Ad}$ & 0,16 Ac & 0,50 Acd & $0,50 \mathrm{Ab}$ \\
\hline 44 & $0,16 \mathrm{Be}$ & $0,50 \mathrm{ABcd}$ & $0,16 \mathrm{Bc}$ & $0,66 \mathrm{ABcd}$ & $1,00 \mathrm{Ab}$ \\
\hline 51 & 0,50 Ade & 0,66 Acd & 0,16 Ac & 0,66 Acd & $0,83 \mathrm{Ab}$ \\
\hline 58 & 1,00 Acd & $1,00 \mathrm{Abc}$ & $1,00 \mathrm{Ab}$ & $1,00 \mathrm{Abc}$ & $0,83 \mathrm{Ab}$ \\
\hline 65 & $1,50 \mathrm{Abc}$ & $1,00 \mathrm{Abc}$ & $1,16 \mathrm{Aab}$ & $1,16 \mathrm{Abc}$ & $1,00 \mathrm{Ab}$ \\
\hline 72 & $2,00 \mathrm{Aab}$ & $1,50 \mathrm{Aab}$ & $1,00 \mathrm{Ab}$ & 1,83Aab & $1,00 \mathrm{Ab}$ \\
\hline 79 & $3,00 \mathrm{Aa}$ & $2,50 \mathrm{Aa}$ & $2,00 \mathrm{Aa}$ & $2,33 \mathrm{Aa}$ & $2,00 \mathrm{Aa}$ \\
\hline
\end{tabular}

(1)Médias seguidas da mesma letra, minúscula nas colunas e maiúscula nas linhas, não diferem entre si pelo teste de Tukey, a 5\% de probabilidade.

Tabela 4. Valores transformados em $(x+0,5)^{0,5}$ da severidade da mancha-de-alternária em folhas das partes inferior, média e superior de genótipos de girassol, provenientes da segunda época de semeadura, avaliados em diferentes períodos após a germinação ${ }^{(1)}$.

\begin{tabular}{|c|c|c|c|c|c|}
\hline Avaliação (dias após germinação) & EMBRAPA-122 & $\mathrm{C}-11$ & M-742 & M-734 & Rumbosol-91 \\
\hline & \multicolumn{5}{|c|}{ Parte inferior da planta } \\
\hline 30 & $4,16 \mathrm{Ab}$ & $4,50 \mathrm{Aa}$ & $4,33 \mathrm{Ab}$ & $4,50 \mathrm{Aa}$ & $4,50 \mathrm{Aa}$ \\
\hline 37 & $4,50 \mathrm{Aab}$ & $4,83 \mathrm{Aa}$ & $4,83 \mathrm{Aab}$ & $4,83 \mathrm{Aa}$ & $4,66 \mathrm{Aa}$ \\
\hline 44 & $4,50 \mathrm{Aab}$ & $4,83 \mathrm{ABa}$ & $4,16 \mathrm{ABb}$ & $4,66 \mathrm{Aa}$ & $4,66 \mathrm{Aa}$ \\
\hline 51 & $4,66 \mathrm{ABab}$ & $4,83 \mathrm{ABa}$ & $4,16 \mathrm{Bb}$ & $4,66 \mathrm{ABa}$ & $5,00 \mathrm{Aa}$ \\
\hline 58 & $5,00 \mathrm{Aa}$ & $5,00 \mathrm{Aa}$ & $4,33 \mathrm{Ab}$ & $5,00 \mathrm{Aa}$ & $5,00 \mathrm{Aa}$ \\
\hline 65 & $5,00 \mathrm{Aa}$ & $5,00 \mathrm{Aa}$ & $5,00 \mathrm{Aa}$ & $5,00 \mathrm{Aa}$ & $5,00 \mathrm{Aa}$ \\
\hline 72 & $5,00 \mathrm{Aa}$ & $5,00 \mathrm{Aa}$ & $5,00 \mathrm{Aa}$ & $5,00 \mathrm{Aa}$ & $5,00 \mathrm{Aa}$ \\
\hline \multirow[t]{2}{*}{79} & $5,00 \mathrm{Aa}$ & $5,00 \mathrm{Aa}$ & $5,00 \mathrm{Aa}$ & $5,00 \mathrm{Aa}$ & $5,00 \mathrm{Aa}$ \\
\hline & \multicolumn{5}{|c|}{ Parte média da planta } \\
\hline 30 & $2,16 \mathrm{Ac}$ & $2,50 \mathrm{Abc}$ & $2,16 \mathrm{Abc}$ & $2,50 \mathrm{Ac}$ & $2,66 \mathrm{Ac}$ \\
\hline 37 & $2,16 \mathrm{Bc}$ & $2,50 \mathrm{Abc}$ & $2,16 \mathrm{Bbc}$ & $3,00 \mathrm{Abc}$ & $3,16 \mathrm{Abc}$ \\
\hline 44 & $2,16 \mathrm{Ac}$ & 2,16 Acd & $1,83 \mathrm{Bc}$ & $2,83 \mathrm{Ac}$ & $3,00 \mathrm{Ac}$ \\
\hline 51 & $2,16 \mathrm{Ac}$ & 2,16 Acd & $2,16 \mathrm{Abc}$ & $2,83 \mathrm{Ac}$ & $3,00 \mathrm{Abc}$ \\
\hline 58 & $2,66 \mathrm{ABc}$ & $2,83 \mathrm{Abc}$ & $2,16 \mathrm{Bbc}$ & $3,16 \mathrm{Abc}$ & $3,00 \mathrm{Ac}$ \\
\hline 65 & $3,66 \mathrm{Ab}$ & $3,00 \mathrm{Ab}$ & $3,00 \mathrm{Aa}$ & $3,16 \mathrm{Abc}$ & $3,66 \mathrm{Aab}$ \\
\hline 72 & $4,16 \mathrm{Aab}$ & $4,00 \mathrm{Aa}$ & $3,16 \mathrm{Aa}$ & $3,83 \mathrm{Aab}$ & $3,33 \mathrm{Aabc}$ \\
\hline \multirow[t]{2}{*}{79} & $4,83 \mathrm{Aa}$ & $4,16 \mathrm{ABa}$ & $3,50 \mathrm{Ba}$ & $4,33 \mathrm{ABa}$ & $4,00 \mathrm{ABa}$ \\
\hline & \multicolumn{5}{|c|}{ Parte superior da planta } \\
\hline 30 & 0,00 Ad & $0,50 \mathrm{Ac}$ & $0,16 \mathrm{Ab}$ & $0,66 \mathrm{Ac}$ & $0,66 \mathrm{Abc}$ \\
\hline 37 & $0,16 \mathrm{Bd}$ & $0,50 \mathrm{ABc}$ & $0,16 \mathrm{Bb}$ & $1,00 \mathrm{Abc}$ & $0,66 \mathrm{ABbc}$ \\
\hline 44 & $1,00 \mathrm{Ac}$ & $1,00 \mathrm{Abc}$ & $0,83 \mathrm{Aa}$ & $1,00 \mathrm{Abc}$ & $0,66 \mathrm{ABbc}$ \\
\hline 51 & $1,00 \mathrm{Ac}$ & $1,00 \mathrm{Abc}$ & $1,00 \mathrm{Aa}$ & $1,00 \mathrm{Abc}$ & $1,00 \mathrm{Aab}$ \\
\hline 58 & $1,00 \mathrm{Ac}$ & $1,00 \mathrm{Abc}$ & $1,00 \mathrm{Aa}$ & $1,00 \mathrm{Abc}$ & $1,00 \mathrm{Aab}$ \\
\hline 65 & $1,50 \mathrm{Abc}$ & $1,50 \mathrm{Aab}$ & $1,16 \mathrm{Aa}$ & $1,50 \mathrm{Aab}$ & $1,66 \mathrm{Aa}$ \\
\hline 72 & $2,00 \mathrm{Aab}$ & $1,50 \mathrm{Aab}$ & $1,16 \mathrm{Aa}$ & $1,50 \mathrm{Aab}$ & $1,16 \mathrm{Aab}$ \\
\hline 79 & $2,83 \mathrm{Aa}$ & $2,00 \mathrm{ABa}$ & $1,50 \mathrm{Ba}$ & $2,00 \mathrm{ABa}$ & $1,83 \mathrm{ABa}$ \\
\hline
\end{tabular}

${ }^{(1)}$ Médias seguidas da mesma letra, minúscula nas colunas e maiúscula nas linhas, não diferem entre si pelo teste de Tukey, a 5\% de probabilidade. 
Nas partes inferior, média e superior, na primeira época, e na parte inferior na segunda, os graus de severidade da mancha-de-alternária, entre as cultivares, não diferiram estatisticamente entre si a partir do final do florescimento (65 dias). Entretanto, na parte média e superior na segunda época de semeadura, a M-742 diferiu significativamente apenas da cultivar EMBRAPA-122, sendo esta semelhante aos demais materiais genéticos.

Em relação ao terço superior das cultivares avaliadas, a incidência da doença foi considerada baixa, variando de $0 \%$ a $4 \%$ de folhas com sintomas durante todo o ciclo em ambas as épocas.

A infestação por $A$. helianthi abrevia o ciclo da planta, em decorrência da redução da atividade fotossintética, conforme Sangoi \& Kruse (1993), que verificaram redução na duração do período de enchimento de grãos das cultivares quando se retardou a semeadura, e fazendo com que a planta se desenvolvesse em condições de temperatura alta e de excesso de chuvas. Mesmo com a alta umidade relativa do ar durante a condução dos ensaios, considerada ideal para o desenvolvimento dessa doença, a sua severidade não foi suficiente para prejudicar o estabelecimento e a produção da cultura. A influência da doença está estreitamente relacionada com a época de semeadura e com os fatores climáticos, como precipitação e umidade relativa do ar.

O índice de precipitação de 420,5 mm (primeira época) e de 397,4 mm (segunda época) ficaram abaixo do índice ideal de precipitação $(650 \mathrm{~mm})$ segundo Siqueira et al. (1980). Apesar disso, a precipitação constante durante todo o ciclo do girassol favoreceu o desenvolvimento da doença.

\section{Conclusões}

1. A população de 42 mil ou 49 mil plantas ha-1 não influencia a severidade da mancha-de-alternária.

2. Todas as cultivares estudadas são suscetíveis à doença.

3. A época de semeadura e os fatores climáticos, principalmente a umidade relativa do ar e a precipitação, afetam o aparecimento e a severidade da mancha-de-alternária.

\section{Referências}

ALESSI, J.; POWER, J. F.; ZIMMERMANN, D. C. Sunflower yield and water use as influenced by planting date, population, and row spacing. Agronomy Journal, Madison, v. 69, p. 465-469, 1977.

BORKAR, S. G.; PATIL, B. S. Epidemiology of alternaria leaf spot disease of sunflower. Indian Phytopathology, New Delhi, v. 48, n. 1, p. 84-85, 1995.

CARSON, M. L. Effects of leaf blight caused by Alternaria helianthi on sunflower seed yields and other agronomic traits. Phytopathology, St. Paul, v. 72, n. 7, p. 984-985, 1982.

CASTIGLIONI, V. B. R.; BALlA, A.; CASTRO, C. de; SILVEIRA, J. M. Fases de desenvolvimento da planta de girassol. Londrina: Embrapa-CNPSo, 1994. 24 p. (Documentos, 58).

CASTro, C. de; CASTiGlioni, V. B. R.; BALLA, A. A cultura do girassol: tecnologia de produção. Londrina: Embrapa-CNPSo, 1996. 20 p. (Documentos, 67).

CHARLET, L. D.; BUSACCA, J. D. Insecticidal control of banded sunflower moth (Cochylis nocres Clep.: Cochylidae) larvae at different sunflower growth stages and dates of planting in North Dakota. Journal of Economic Entomology, Lanham, v. 79, p. 648-650, 1986.

EVERSMEYER, M. G.; BURLEIGH, J. R. A method of predicting epidemic development of wheat leaf rust. Phytopathology, St. Paul, v. 60, p. 805-811, 1970.

FREZZI, M. J.; GIORDA, L. M.; LJUBICH, A. Helminthosporium helianthi Hansford: agente causal de la "Helmintosporiosis" del girasol (Helianthus annuus L.) en Argentina. Córdoba: Instituto Nacional de Tecnología Agropecuaria, 1979. (Información Técnica, 83).

HANSFORD, C. G. Contributions towards the fungal flora of Uganda. V. Fungi imperfect. Proceedings of Linnean Society, London, v. 1, p. 34-67, 1943.

KINMAN, M. L.; SARLE, F. R. Agronomic performance and chemical composition of the seed of sunflower hybrids and introduced varieties. Crop Science, Madison, v. 4, n. 3, p. 417-420, 1984.

LAWN, R. J.; WILLIAMS, J. H. Limits imposed by climatological factors. In: FOOD LEGUME IMPROVEMENT FOR ASIAN FARMING SYSTEMS INTERNATIONAL WORKSHOP, 1986, Khon Kaen. Proceedings... Canberra: Australian Center for International Agricultural Research, 1987. p. 83-98. (ACIAR Proceedings, 18).

LEITE, R. M. V. B. C. Doenças do girassol. Londrina: Embrapa-CNPSo, 1997. 68 p. (Circular Técnica, 19). 
LEITE, R. M. V. B. C.; TREZZI, M. M.; OLIVEIRA, M. F.; ARIAS, C. A. A.; CASTIGLIONI, V. B. R. Reaction of sunflower genotypes to Alternaria helianthi in the state of Paraná, Brazil. Helia, Novi Sad, v. 22, n. 31, p. 151-158, 1999.

MORAES, S. A.; UNGARO, M. R. G.; MENDES, B. M. J. "Alternaria helianhti”: agente causal de doença em girassol. Campinas: Fundação Cargill, 1983. 20 p.

SANGOI, L.; KRUSE, N. D. Comportamento de cultivares de girassol em diferentes épocas de semeadura no planalto catarinense. Pesquisa Agropecuária Brasileira, Brasília, v. 28, n. 1, p. 81-91, jan. 1993.
SEILER, G. J. Effect of genotype, flowering date, and environment on oil content and oil quality of wild sunflower seed. Crop Science, Madison, v. 23, p. 1063-1068, 1983.

SENTELHAS, P. C.; PEZZOPANE, J. R. M.; UNGARO, M. R. G.; MORAES, S. A.; DUDIENAS, C. Aspectos climáticos relacionados à ocorrência da mancha de alternária em cultivares de girassol. Fitopatologia Brasileira, Brasília, v. 21, n. 4, p. 464-469, 1996.

SIQUEIRA, I. F. de; VIEIRA, L. G. E.; COSTA, A.; NAZARENO, N. R. X. de; PIZZAMIGLIO, M. A.; GRODZIKI, L. Girassol. In: FUNDAÇÃO INSTITUTO AGRONÔMICO DO PARANÁ (Londrina, PR). Manual agropecuário para o Paraná. Londrina, 1980. p. $178-215$. 